\title{
Encarceramento juvenil: o legado histórico de seletividade e criminalização da pobreza
}

\author{
Bruna Carolina Bonalume ${ }^{1,2}$ \\ https://orcid.org/0000-0002-4109-5435
}

\author{
Adriana Giaqueto Jacinto ${ }^{1}$ \\ https://orcid.org/0000-0003-0181-2839
}

${ }^{1}$ Universidade Estadual Paulista “Júlio de Mesquita Filho”, Faculdade de Ciências Humanas e Sociais, Programa de Pós-Graduação em Serviço Social, Franca, SP, Brasil

${ }^{2}$ Tribunal de Justiça do Estado de São Paulo, Comarca de São Manuel, São Manuel, SP, Brasil

\section{Encarceramento juvenil: o legado histórico de seletividade e criminalização da pobreza}

Resumo: O presente artigo tem como objetivo propor reflexões acerca do encarceramento juvenil, bem como sobre a maneira como a violência atravessa o cotidiano dessa população. Essa discussão está pautada no reconhecimento da seletividade da justiça frente a uma sociedade marcada profundamente pela desigualdade de gênero, classe social e raça/etnia. Para adentrar nesse cenário serão tecidas discussões construídas na perspectiva de contextualizar a questão social, suas expressões e o modo como o Estado historicamente tem respondido, ou seja, com coerção e consenso, o que revela o quanto o enfrentamento dessa realidade tem suas raízes fundadas em uma sociedade desigual e que sustenta uma lógica de criminalização da pobreza.

Palavras-chave: Encarceramento juvenil. Seletividade. Criminalização da pobreza.

\section{Juvenile incarceration: The historical legacy of selectivity and criminalization of poverty}

Abstract: This article discusses the issue of juvenile incarceration and how violence is present in the daily life of this population. The reflections are based on the recognition of the selectivity of justice in a society deeply marked by the inequality of gender, social class, and ethnicity. The discussions are carried out with the intention to provide the context of the social aspect, its expressions, and the way the state has historically addressed the issue - with coercion and consensus - revealing how the confrontation of this reality has roots in an unequal society supporting a notion of criminalization of poverty.

Keywords: Juvenile imprisonment. Selectivity. Criminalization of poverty.

Recebido em 01.06.2018. Aprovado em 18.09.2018. Revisado em 22.01.2018.

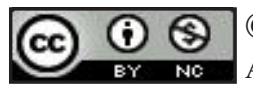

(C) O(s) Autor(es). 2019 Acesso Aberto Esta obra está licenciada sob os termos da Licença Creative Commons Atribuição-NãoComercial 4.0 Internacional (https://creativecommons.org/licenses/by-nc/4.0/deed.pt_BR), que permite copiar, distribuir e reproduzir em qualquer meio, bem como adaptar, transformar e criar a partir deste material, desde que para fins não comerciais e que você forneça o devido crédito aos autores e a fonte, insira um link para a Licença Creative Commons e indique se mudanças foram feitas. 


\section{Introdução}

Os debates em torno da juventude brasileira têm recebido certa notoriedade no conjunto da sociedade, seja no âmbito acadêmico, sociojurídico ou mesmo nos processos de militância em defesa dos direitos dessa população. Não se pode negar, ainda, que no bojo desses debates são incorporadas as discussões midiáticas, que, sobretudo ao tratarem do tema relacionado ao ato infracional, fortalecem a ideia de associação da imagem desses jovens à vadiagem e à periculosidade. Neste contexto, um questionamento é inevitável, qual seja, a respeito de qual juventude se fala?

Cabe reconhecer primeiramente que há lugares diferentes a serem ocupados pelos sujeitos sociais, os quais são legitimados pelo modelo de uma sociedade dividida em classes e regida pela ordem capitalista. Assim, a juventude a qual nos referimos é aquela que vive nas periferias, jovens negros, pobres, que vivenciam a intensificação das expressões da questão social, o processo desenfreado da criminalização e marginalização da pobreza. Jovens que enfrentam uma verdadeira batalha pela sobrevivência em uma sociedade que privilegia uma classe sobre a outra, explora, segrega e assume formas cada vez mais violentas, opressoras e moralizantes como forma de garantir a ordem social, mas o fato é que esse modelo tem impacto direto na produção e reprodução da condição de vida desses adolescentes, principalmente daqueles que cometeram atos infracionais.

Nesse cenário, o Estado revela o seu papel punitivo em detrimento da garantia da proteção integral. Desse modo, as poucas e tímidas tentativas de oferecer resposta às expressões da questão social na cena contemporânea, pautase na adoção de medidas coercitivas para se reestabelecer a ordem pública, sustentando a falsa promessa de uma cultura de paz em defesa de uma sociedade que também clama por justiça, como se essa pudesse ser legitimada com a adoção de um sistema opressor e eficaz, capaz de garantir o encarceramento indiscriminado dessa população.

Com base nessas discussões, o presente artigo tem como objetivo propor reflexões acerca do encarceramento juvenil e como a violência atravessa o cotidiano dessa população. Para adentrar nesse cenário serão apresentadas discussões acerca da intensificação das expressões da questão social e o modo como historicamente o Estado legitima

\section{Esse debate está longe de ser} findado, pois revela que ainda hoje, mesmo tendo decorrido 28 anos da promulgação do ECA, ainda permanecemos atônitos diante da velha questão que coloca 0 adolescente e o jovem brasileiro entre a escassa

proteção e o devasso controle repressivo, o que resulta no encarceramento dessa população e legitima o silêncio e o desprezo pelo jovem, negro, morador das periferias. sua ação controladora e repressiva como parte integrante de um projeto societário pautado e regido pelo sistema capitalista. A partir disso, busca-se trazer à tona a trajetória sócio-histórica da política de atenção à infầncia, adolescência e juventude no Brasil, observadas as conquistas, desafios e retrocessos sobretudo quando os discursos se centram na situação dos adolescentes e jovens infratores. Por fim, são apresentados dados da política de encarceramento juvenil que contrastam com dados da violência e do extermínio desses sujeitos sociais.

\section{Questão social e Estado Penal: incongruências de um discurso nem sempre convincente}

O tempo presente tem sido marcado por retrocessos dos direitos sociais, avanço do conservadorismo, valorização de discursos e práticas que demarcam o cunho coercitivo e opressor do modo como o Estado responde à intensificação das expressões da questão social. Além disso, estamos imersos em uma crise política, econômica e ética sem precedentes, que parece colocar em xeque até mesmo o processo democrático brasileiro.

As desigualdades sociais, consolidadas no modelo vigente de sociedade, são resultado da riqueza socialmente produzida e acessada por poucos, bem como do processo de concentração do poder. A pobreza se alastra ao passo que aumenta a distância entre ricos e pobres no Brasil, o que não se trata de uma mera coincidência. Vivemos uma realidade em que a ampliação das riquezas contrasta fortemente com o aprofundamento da miséria. 
Tavares (2009) contribui com nossa reflexão, comentando que o modo como mundialmente se organiza a produção traduz uma longa história de exploração do homem pelo homem, cujas relações sociais são determinadas pelo escravismo, pelo feudalismo e, contemporaneamente, pelo capitalismo. $\mathrm{O}$ autor acrescenta que todas essas formações sociais são compostas por classes antagônicas, isto é, por dominantes e dominados. Na sociedade capitalista, a vida do trabalhador não impõe limites à produção. Ainda assim, todas têm em comum a desigualdade, mas isso não é argumento suficiente para se afirmar que a divisão da sociedade em classes seja algo natural. E, cita Marx (1988, p. 140): "A natureza não produz de um lado possuidores de dinheiro e de mercadorias e, de outro, meros possuidores das próprias forças de trabalho".

Paulo Netto (2001, p. 46) reflete que o que distingue a exploração no capitalismo de outros sistemas anteriores é que não seria necessária a exploração do trabalho para a produção de riqueza, ou seja, é possível produzir riqueza sem a exploração do trabalho:

A exploração não é um traço distintivo do regime do capital (sabe-se, de fato, que formas sociais assentadas na exploração precedem largamente a ordem burguesa); o que é distintivo desse regime é que a exploração se efetiva num marco de contradições e antagonismos que a tornam, pela primeira vez na história registrada, suprimível sem a supressão das condições nas quais se cria exponencialmente a riqueza social. Ou seja: a supressão da exploração do trabalho pelo capital, constituída a ordem burguesa e altamente desenvolvidas as forças produtivas, não implica - bem ao contrário! - redução da produção de riquezas.

Nesta linha de raciocínio, é que podemos dizer que acumulação e desigualdade são indissociáveis do capitalismo, uma vez que o progressivo aumento da riqueza constitui também ampliação da pobreza.

Nesse sentido, Paulo Netto (2007, p. 142) também destaca que "[...] o desenvolvimento capitalista é necessário e, irredutivelmente, produção exponenciada de riqueza e produção reiterada da pobreza [...]", portanto, resultante do modo de divisão de bens onde o trabalhador assalariado produz riquezas, porém essas não serão apropriadas por ele e sim acumuladas por uma classe dominante (SIQUEIRA, 2013). Para Iamamoto (2011, p. 128-129):

[...] tais desigualdades revelam o descompasso entre temporalidades históricas distintas, mas coetaneamente articuladas, atribuindo particularidades à formação social do País. Afetam a economia, a politica e a cultura, redimensionando, simultaneamente, nossa herança histórica e o presente. Imprimem um ritmo particular ao processo de mudanças em que tanto o novo quanto o velho alternam-se em direções contrapostas: a modernidade das forças produtivas do trabalho social convive com padrões retrógados nas relações no trabalho, radicalizando a questão social.

Essa lógica sustenta a estrutura do capital e se propaga por todas as esferas da vida social, sobretudo da classe trabalhadora que é forjada a vender a sua força de trabalho como forma de garantir o mínimo para a sobrevivência. Para isso, além de polivalente, precisa submeter-se à exploração e precarização das relações de trabalho, o que inclui a ampliação da jornada, redução de postos, funções repetitivas e mecanizadas em troca de um salário irrisório.

Nesse cenário, Iamamoto (2011, p. 144-145), ainda, destaca que há um processo de metamorfose no que considera ser a velha questão social, que se reveste agora com outras roupagens:

Ela evidencia hoje a imensa fratura entre o desenvolvimento das forças produtivas do trabalho social e as relações sociais que o impulsionam. Fratura esta que vem se traduzindo na banalização da vida humana, na violência escondida no fetiche do dinheiro e da mistificação do capital ao impregnar todos os espaços e esferas da vida social. Violência que tem no aparato repressivo do Estado, capturado pelas finanças e colocado a serviço da propriedade e poder dos que dominam, o seu escudo de proteção e de disseminação.

Essas fraturas apontadas por Iamamoto (2011) se intensificam e se particularizam com a legitimação de um Estado repressor e punitivo. Evidentemente que essas particularidades do Estado não se destinam a todos os sujeitos sociais, mas à população pobre, produzida e reproduzida no contexto da exploração capitalista. A essa caberá a vigilância e o controle, e, ao passo que essa relação se estabelece, a pobreza é legitimada como perigosa, não restando alternativa para o Estado a não ser puni-la para preservação da ordem.

Nesse âmbito, é fortalecida a lógica de controle social que visa o estabelecimento da dinâmica e da ordem capitalista. Cabe considerar que o controle social está presente em todas as formas de sociedade e se mediatiza nas diferentes dimensões da vida, "[...] sendo necessário ao intercâmbio do homem com a natureza [...]" (SILVA, 2011, p. 40). No entanto, nos marcos da expansão capitalista, a autora destaca que: 
[...] o controle social ganha sentidos, significados e assume forma histórica nos diferentes modos de produção social. Na sociedade capitalista, o controle é construído socialmente nos diferentes sistemas de poder, sob o domínio do capital, que usa o controle social em defesa da sociedade de classes, da propriedade privada, da exploração do trabalho e da cultura de elite, de modo a reproduzir de geração em geração a necessidade da existência do controle social dominante, que confirma a aparente legalidade dos de domínio como verdade. (SILVA, 2011, p. 40).

Isso posto, Mészáros (2002, p. 989) enfatiza que a raiz da questão não está no fato de produzirmos ou não formas de controle, mas, sim, o "[...] tipo de controle, dado que as condições atuais foram produzidas sob o férreo controle do capital que nossos políticos pretendem perpetuar como força reguladora fundamental de nossas vidas".

Essa força reguladora descrita pelo autor se consolida como um mecanismo essencial à manutenção do sistema capitalista, da ordem burguesa, sendo possível afirmar que o próprio processo de criminalização da pobreza se constitui como uma instância de controle social na cena contemporânea.

Desse modo, o controle social legitimado por essa via possui como pano de fundo a propagação de um ideário burguês que responsabiliza, sobretudo, a classe trabalhadora, pela precária condição de vida, pela exploração do trabalho e até mesmo pela intensificação da violência, o que justificaria o ostensivo avanço da ampliação indiscriminada da intervenção penal.

Para Wacquant (2008, p. 466):

[...] o surgimento do Estado Penal é o resultado de uma política de penalização da miséria, que responde ao crescimento da insegurança salarial e ao aprofundamento do gueto como mecanismo de controle de uma população duplamente marginalizada no duplo plano material e simbólico.

Segundo Wacquant (2001), essa política de criminalização da pobreza e gestão da miséria gerenciada pela lógica do Estado Penal se dá em duas modalidades. O primeiro componente do Estado Penal refere-se à transformação das políticas sociais em instrumentos de controle e vigilância, sobretudo da população pobre e considerada como perigosa. O segundo componente é o encarceramento ou a repressão ofensiva sobre essa mesma população, que atinge prioritariamente negros e jovens moradores da periferia. Wacquant (2001) aponta que a força desse segundo componente tem como traço característico o avanço neoliberal, que envolve a visível diminuição do orçamento das políticas sociais em detrimento do crescente orçamento das políticas penais/criminais. E ainda, a ampliação do número de prisões privadas como nicho lucrativo e as estatísticas de jovens apreendidos bem como os atos cometidos, que revelam que na atualidade há um aumento de jovens cumprindo medidas de privação de liberdade por atos menos graves.

Nessa conjuntura, tem-se, então, um Estado que não se intimida em reprimir a gigantesca massa de miseráveis engendrada pela reestruturação contemporânea do capital. Ao contrário disso, sua intervenção se pauta no fortalecimento da coerção, o que evidencia a audaciosa manutenção da ordem estabelecida, dos distintos lugares a serem ocupados nessa divisão de classes socialmente estabelecida, que desenha a relação entre o aparato estatal coercitivo e pobreza sob a vigência neoliberal.

E quais seriam os rebatimentos dessa lógica junto à adolescência e juventude brasileiras? Como falarmos em proteção social desse grupo populacional, se a prioridade é a manutenção da divisão de classes? Como ampliarmos o debate em torno da luta por direitos quando o legado histórico da política voltada à infância e juventude nos revela que a punição e o controle se reafirmam diante de interesses dominantes?

\section{O legado histórico de um estado de punição e repressão da juventude brasileira}

Quando se pensa em ato infracional o que temos é uma trajetória sócio-histórica que ao longo de seu desenvolvimento construiu e legitimou as estratégias de coerção e repressão, história essa que pouco tem a ver com direitos sociais.

Evidentemente que não se pode ignorar toda a trajetória histórica de luta e resistência e intensa mobilização social que resultou na promulgação do Estatuto da Criança e Adolescente (ECA), porém ainda não é possível afirmarmos que a lógica de proteção integral e efetivação de direitos está consolidada.

Nesse contexto, concordamos com Arendt (2009, p. 33), quando diz que para se entender a realidade atual é preciso lançar o olhar sobre as "brechas" deixadas pelo passado, com base nas quais é possível compreender o futuro. Ratifica-se que as brechas do passado são históricas, sendo necessário entender as particularidades da constituição da violência e suas manifestações na realidade brasileira, considerando as mudanças no desenvolvimento da história. 
Para Silva (2011, p. 52), ao longo da história a atenção à infância e adolescência, sobretudo pobre, recebe atenção ora de caráter de "compaixão/punição", ora de "sanção/punição", o que, para a autora, revela o caráter contraditório de práticas educativas, assistenciais e sociojurídicas e que "[...] imprimem uma determinada proposta de controle sociopenal”. (SILVA, 2011, p. 69).

Para revisitar essa história que demarca o processo de responsabilização e controle sociopenal, optamos pela divisão sócio-histórica elaborada por Mendez (2000). O referido autor compreende que a responsabilidade penal é consolidada na América Latina e no Brasil em três diferentes etapas: a primeira refere-se à de "[...] caráter penal indiferenciado, que estende-se desde o nascimento dos códigos penais de corte claramente retribucionista do século XIX até 1919". (MENDEZ, 2000, p. 1, grifo do autor). Para o autor, esse período demarca a compreensão de que crianças e adolescentes não se diferenciavam dos adultos e no Brasil, mais especificamente, esse momento surge com o primeiro Código Criminal de 1830 e estende-se ao longo de 97 anos até a promulgação do primeiro Código de Menores de 1927.

Rizzini (2011a) menciona que a lei estabelecia a idade penal aos 14 anos e, portanto, a autoridade policial poderia recolher o adolescente nas Casas de Correção, quando esses cometessem qualquer tipo de crime. A autora (RIZZINI, 2011a) destaca que logo em 1888, na Câmara dos Deputados do Rio de Janeiro, tramitava o Projeto de Número 33-A, cuja proposta centrava-se na repressão e correção de adolescentes considerados ociosos na medida que habitualmente perambulavam pelas vias públicas. Havia, portanto, a necessidade de uma atenção jurídica a esses sujeitos, por meio da aplicação de medidas mais drásticas, a fim de impedir o que claramente se constituía como um incômodo e uma ameaça à harmonia, aos bons costumes e à tranquilidade social.

Ainda na perspectiva da autora (RIZZINI, 2011a, p. 115), essa preocupação em reprimir o ócio configurava-se como parte do inevitável processo de transformação "[...] das relações socioeconômicas neste período de transição para a ordem capitalista". Desse modo, a questão dizia respeito à construção de uma nova ideologia do trabalho, com valores nacionalistas, que superasse a lógica de sujeitos preguiçosos, tão associada ao modelo de sociedade colonial, para atingirem os padrões de países europeus, pois assim tornaria possível o amplo acesso do capital.

A segunda etapa dessa divisão sócio-histórica é denomina por Mendez (2000, p. 1) como "tutelar". Para o autor,

Esta etapa tem sua origem nos EEUU de fins do século XIX, é liderada pelo chamado Movimento dos Reformadores e responde a uma reação de profunda indignação moral frente à promiscuidade do alojamento de maiores e menores nas mesmas instituições. A partir da experiência dos EEUU, que a especialização do direito e a administração da justiça de menores se introduz na América Latina. (MENDEZ, 2000, p. 1).

No Brasil, esse período tem como marco a promulgação do Código de Menores Mello Mattos de 1927. O Código, apesar de estabelecer tentativas de romper com a visão tradicionalista anteriormente instituída, mostra-se pouco revolucionário ao categorizar a infância e a adolescência como menores abandonados ou pervertidos. Para Faleiros (2011, p. 47), o "Código de 1927 incorpora tanto a visão higienista de proteção do meio e do indivíduo, como a visão jurídica repressiva e moralista [...]", valendo-se de modelos correcionais cuja filosofia política pautava-se no controle social.

O governo Vargas inaugurou políticas que não superaram o tom autoritário, repressivo, paternalista e clientelista do Estado Novo e criou em 1941 o Serviço de Assistência ao Menor (SAM). Esse modelo, segundo Rizzini (2011b, p. 266), foi duramente criticado pela sociedade, pois transformava seus internatos em "verdadeiras sucursais do inferno", em decorrência da sua estrutura e funcionamento análogos ao sistema prisional, que mascaravam verdadeiras atrocidades e violação de direitos. E ainda:

[...] a filosofia do SAM era fundamentada na criminologia positivista europeia do século XIX, onde era dada ênfase às ciências biológicas e psicológicas para explicitar cientificamente as condutas patológicas e sadias. É a partir desse enfoque que nasce a terminologia "delinquente", utilizada preconceituosamente para demarcar o comportamento juvenil considerado problemático, uma ameaça em potencial. (COSTA, 1990, apud SILVA, 2011, p. 83).

Já em 1964, devido à articulação realizada no meio social, institucional e partidário para se extinguir o SAM, mediante resistência do Ministério da Justiça, a Política Nacional do Bem Estar do Menor, recentemente criada, institui a Fundação Nacional de Bem Estar do Menor (FUNABEM), com meta inversa ao do SAM, seus objetos eram: "[...] autonomia financeira e administrativa da instituição e na rejeição aos depósitos de menores". (RIZZINI, 2004, p. 35). Porém, tal filosofia não superou o modelo repressivo, tendo em vista que o cenário político do País sofre com a ostensiva vigilância e controle do militarismo. 
Dentro desta perspectiva de vigilância, em 10 de novembro de 1979, institui-se o Novo Código de Menores, sob a doutrina da situação irregular. Faleiros (2011, p. 70) destaca que a situação irregular é definida como "[...] a privação de condições essenciais à subsistência, saúde e instrução, por omissão, ação ou irresponsabilidade dos pais ou responsáveis". Tal concepção torna a "[...] questão ainda mais jurídica e assistencial, dando-se ao juiz o poder de decidir sobre o que seja melhor para o menor: assistência, proteção ou vigilância". (FALEIROS, 2011, p. 70).

A atenção em torno da infância e adolescência vai se desenhando no País nessa trajetória histórica sem superar modelos punitivos e discriminatórios, que revelam o papel de tutela que o Estado assume perante esse grupo, com fins de controle, vigilância e sanções para aqueles que não se adaptam às normas vigentes da classe dominante. Para Silva (2011, p. 87):

Esse sistema selou, de uma vez por todas, o controle social institucional desse segmento numa articulação dos poderes Executivo, Legislativo e Judiciário. Pois o sistema tutelar foi criado para tratar dos sintomas da 'inadaptação social', como antidoto à 'delinquência juvenil', oriunda do suposto 'abandono moral'.

É na terceira etapa, definida por Mendez (2000) como responsabilidade penal dos adolescentes, que se inicia a tentativa de ruptura com modelos anteriormente instituídos, para adoção de um modelo pautado na justiça e na garantia de direitos.

Essa etapa é inaugurada no Brasil no ano de 1990 com a promulgação do ECA, quando passa a ser adotada a doutrina da proteção integral que reconhece a criança e o adolescente como sujeitos de direitos e não mais meros objetos de intervenção jurídica-estatal, bem como estabelece medidas de prevenção, proteção, uma política especial de atendimento e um acesso digno à justiça.

Evidentemente, o ECA representa uma construção social advinda de uma luta sócio-histórica em um contexto neoliberal, porém ainda é necessário reconhecer que se trata de um campo de tensões, contradições e jogo de interesse, já que estamos diante de um Estado burguês, cujo projeto societário permanece inalterado, sendo que a sua estrutura está intimamente enraizada na lógica de um sistema capitalista, o que contribui para sustentação de respostas estatais repressoras e controladoras.

Nessa perspectiva Silva (2011, p. 121) destaca que:

[...] embora existam majoritariamente, interpretações de que o ECA é destinado a todas as crianças e adolescentes, indistintamente de sua condição social, seus fundamentos sócio-históricos e jurídico possibilitam inferir que, à semelhança do Código de Menores, ele não libertou das prisões adolescente pobres e infratores. Continua destinado à população pobre, potencialmente 'perigosa' e 'delinquente'. A relação pobreza e delinquência foi adaptada para pobreza e infração, mantendo-a atualizada na medida em que são os pobres que, na sua maioria, são privados de liberdade.

Esse debate está longe de ser findado, pois revela que ainda hoje, mesmo tendo decorrido 28 anos da promulgação do ECA, ainda permanecemos atônitos diante da velha questão que coloca o adolescente e o jovem brasileiro entre a escassa proteção e o devasso controle repressivo, o que resulta no encarceramento dessa população e legitima o silêncio e o desprezo pelo jovem, negro, morador das periferias.

\section{Encarceramento da adolescência e juventude: a quem interessa esse debate?}

A adolescência é definida, segundo o ECA (BRASIL, [2019]), como o período que se estende dos 12 aos 18 anos incompletos. Já o Estatuto da Juventude (EJUVE) (BRASIL, [2018]), promulgado em 2013, define a juventude como as pessoas entre faixa etária de 15 a 29 anos. Destacar essa divisão etária tem como objetivo situar o grupo social ao qual se refere o presente artigo.

É valido frisar que o EJUVE não dispõe de menções específicas quando o tema é ato infracional, desse modo os jovens que possuem entre 15 e 18 anos incompletos, quando cometem ato infracional de qualquer natureza, a medida aplicada é de caráter socioeducativo e baseia-se nos princípios do ECA, já os jovens que possuem mais de 18 anos respondem aos processos mediante o Código Penal Brasileiro.

Para além das delimitações etárias, o fato é que estamos diante de um intenso e complexo cenário social, quando as discussões se centram nos dados sobre encarceramento dessa população.

Segundos dados do Mapa do Encarceramento (BRASIL, 2015), houve em um período de sete anos um aumento significativo da população carcerária, sobretudo entre os jovens que estão na faixa etária entre 18 e 24 anos. No ano de 2005 eram 96.288 jovens encarcerados, mas no ano de 2012 registra-se 266.356 presos 
nessa mesma faixa etária. Os dados ainda revelam que a maioria não havia completado o ensino fundamental, bem como não estava inserida em postos de trabalho formais.

O referido documento (BRASIL, 2015) aponta, também, que no ano de 2012, o encarceramento de jovens foi 2,5 vezes maior do que o de não jovens. No que se refere a grupo étnico-racial $60,8 \%$ da população carcerária eram de negros, além do que, estes foram encarcerados 1,5\% a mais que os brancos (BRASIL, 2015).

Com base no cenário descrito é possível destacar que o aprisionamento no Brasil historicamente carrega um corte de raça e classe que está intimamente relacionado à herança escravocrata que evidencia a questão étnico-racial como um elemento central junto às múltiplas violações de direitos. Tal fato revela que "O racismo continua oferecendo aos aparatos de repressão os elementos ideológicos que legitimam o livre uso da força do Estado [...]" (FAUSTINO, 2010, p. 24-25). Trata-se, portanto, de reconhecer que "[...] a polícia militar não invade do mesmo jeito a cobertura do descendente do escravizador e o barraco do descendente do escravizado. O passado, como uma pedra jogada na água, cria ondas concêntricas que repercutem no presente". (CASTRO, 2016, p. 23).

No que se refere à população adolescente, o ECA (BRASIL, [2019]) estabelece em seu art. 112 que verificada a prática de ato infracional, a autoridade competente poderá aplicar ao adolescente as seguintes medidas socioeducativas: advertência; obrigação de reparar o dano; prestação de serviço à comunidade; liberdade assistida; inserção em regime de semiliberdade e internação em estabelecimento educacional, cabendo ressaltar que essa última se constitui como medida privativa de liberdade e está sujeita aos princípios de brevidade, excecionalidade e respeito à condição peculiar de pessoa em desenvolvimento.

Por outro lado, segundo dados do Levantamento Anual do Sistema Nacional de Atendimento Socioeducativo (SINASE) (BRASIL, 2018), referente ao ano de 2015, revela que a medida socioeducativa de internação, que deveria ser aplicada em caráter de exceção, representa mais de $68 \%$ dentre todas as medidas aplicadas no Brasil e no conjunto de uma série histórica tem visível crescimento, conforme apresentado no Gráfico 1.

\section{Gráfico 1 - Adolescentes e Jovens em Internação, Internação Provisória e Semiliberdade (2010-2015)}

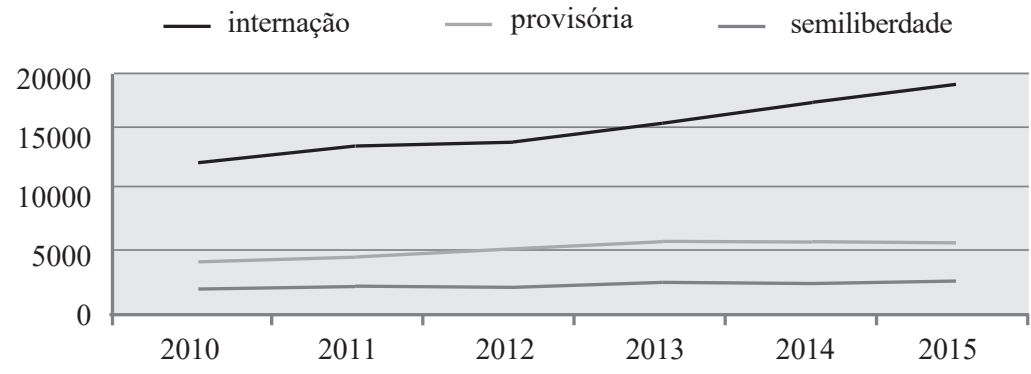

Fonte: Elaborado a partir dos dados de Brasil, 2018.

Neste mesmo levantamento (BRASIL, 2018) registrou-se que os atos infracionais análogos ao roubo representaram $46 \%$ (12.724), 24\% (6.666) como análogo ao tráfico de drogas e 10\% (2.788) análogo ao homicídio. Embora o ato infracional análogo ao homicídio, considerado de maior gravidade, represente $10 \%$ do total de registros, o roupo e o tráfico parecem receber a mesma equiparação quando observamos a porcentagem da aplicação da medida de internação.

O perfil dos adolescentes ainda é mais elucidativo, quando o levantamento aponta que em relação à questão de gênero, há predominância de adolescentes do sexo masculino $(96 \%)$, e concentração na faixa etária entre 16 e 17 anos com 57\% (BRASIL, 2018). Quando analisamos o perfil étnico-racial, nos deparamos com situações semelhantes àquelas observadas nos dados do encarceramento juvenil, e não parece tratar-se apenas de uma mera eventualidade. 
Gráfico 2 - Porcentagem de Adolescentes e Jovens por Raça/Cor em Restrição e Privação de Liberdade

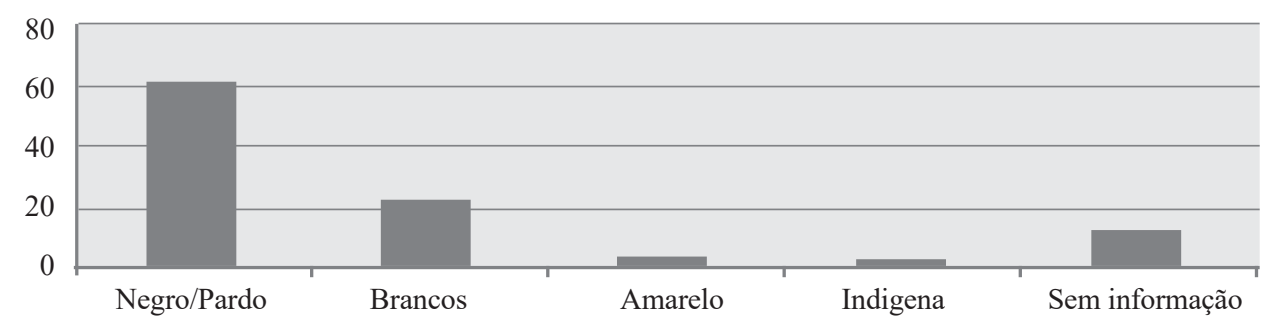

Fonte: Elaborado a partir dos dados de Brasil, 2018.

Os dados revelam as tensões e contradições do tempo presente que se situam entre a proteção e a punição, o que evidencia a necessidade de um amplo e sério debate em torno da questão, já que privilegiar medidas de coerção e repressão em detrimento da proteção social é caminhar na contramão das lutas em defesa dos direitos de adolescentes e jovens, sobretudo de negros, pobres e moradores da favela, que de forma violenta adentram no sistema judiciário pela via do encarceramento.

Nesse sentido, destacam-se os estudos de Adorno (2003) que ao discutir a relação entre justiça, igualdade jurídica e juízo, sob o ponto de vista da influência do racismo e dos preconceitos raciais na distribuição da justiça penal conclui que embora o crime não seja cometido apenas pela população negra, a punição sim é voltada a esse grupo.

\section{O outro lado da mesma moeda: vidas estilhaçadas}

Quando tratamos de proteção social, parece que ainda não ultrapassamos o plano dos aparatos legislativos. Ao passo que cresce a perspectiva de encarceramento, cresce também o extermínio da juventude brasileira em um evidente recorte étnico-racial e de classe social.

Dados do Índice de Vulnerabilidade Juvenil à Violência do ano de 2017, desenvolvido pela Secretaria Nacional de Juventude em parceria com o Fórum Brasileiro de Segurança Pública, revelam um quadro que nada se relaciona com a lógica de proteção social (BRASIL, 2017).

Nesse documento é possível observar que no Brasil o risco relativo de um jovem negro ser vítima de homicídio em relação a um jovem branco é de 2,7 sendo que esses dados se tornam mais assustadores quando olhamos para cenários como da região Nordeste, que atinge o percentual de 8,9 no estado da Paraíba.

A taxa de homicídios entre os jovens negros nos revela um descarado processo de reprodução de uma sociedade escravocrata, cuja herança atinge visceralmente a vida desses sujeitos sociais, como é possível observar no Gráfico 3.

\section{Gráfico 3 - Taxa de homicídios de homens e mulheres negras e não negras}

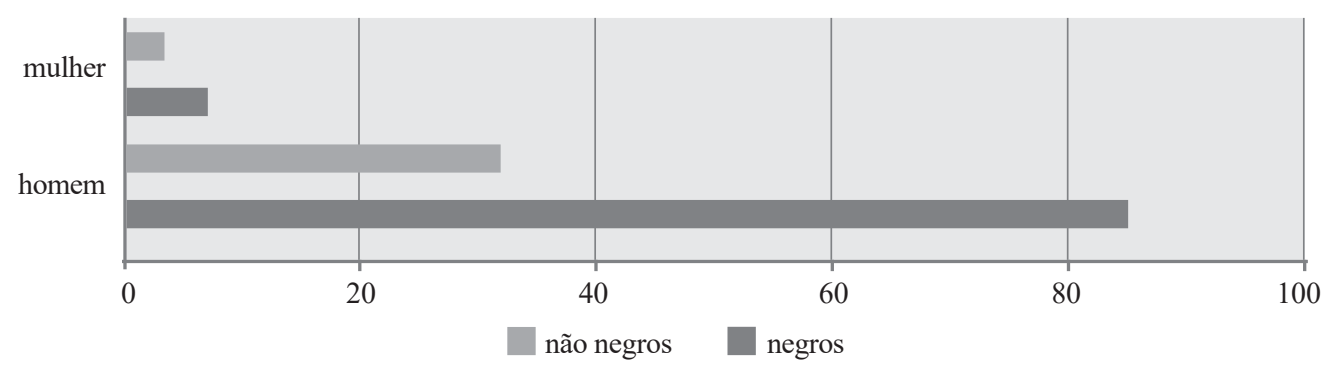

Fonte: Elaborado a partir dos dados de Brasil, 2017. 
Nessa mesma perspectiva os dados do Atlas da Violência 2017 (CERQUEIRA et al., 2017) mostram que mais da metade das 59.080 pessoas mortas por homicídios em 2015 eram jovens (31.264, equivalentes a $54,1 \%$ ), dos quais $71 \%$ eram negros e $92 \%$ do sexo masculino.

Um verdadeiro genocídio, uma grave violação de direitos humanos, uma violência que impede que parte significativa dos jovens brasileiros tenha uma vida plena e revela uma inesgotável ineficiência de um Estado que não garante nem mesmo a sobrevivência dessa população.

Outro dado significativo é a seletividade racial dos homicídios por armas de fogo. A taxa de homicídios por armas de fogo de jovens brancos no Brasil caiu, enquanto de jovens negros aumentou. "[...] a vitimização negra do país, que em 2003 era de 72,5\%, em poucos anos duplica. Em 2012 é de 142\% [...]" (WAISELFISZ, 2015 , p. 101). Isso significa que morrem 2,5 vezes mais negros que brancos vitimados por arma de fogo (WAISELFISZ, 2015). O número de mortes de jovens do sexo masculino é extremamente superior ao feminino, totalizando $95 \%$ de óbitos para o sexo masculino contra apenas $5 \%$ para o feminino, dentre todas as causas de mortes por armas de fogo na população jovem em 2012 no Brasil (WAISELFISZ, 2015).

Em meio a esse campo de extermínio nos deparamos com o discurso societário, que criminaliza e atribui à população negra a responsabilidade de inserção nessa conjuntura tão perversa, conduzida pela ordem social vigente.

Tal discurso ignora a barbárie a que essa população foi submetida ao logo da violenta história vivida no cenário brasileiro. Mas o que interessa de fato é a história contada pelas classes dominantes, que disseminam em seu discurso classista e racista a ideia de que essa população é potencialmente perigosa e deve ser punida e banida do conjunto da sociedade (ADORNO, 2003).

Olhando para esse cenário, ao invés de perspectiva de futuro temos a ausência de direitos. Ao invés de políticas públicas efetivas de educação, temos planos de encarceramento massivo. Ao invés de liberdade temos um contínuo das algemas da escravização. Opera-se, portanto, a criminalização da juventude, sobretudo da juventude pobre e negra.

\section{Considerações finais}

O encarceramento da juventude brasileira é atravessado por várias concepções e ideologias, bem como por projetos antagônicos em disputa na sociedade, os quais estão alicerçados em uma sociedade de classes regida pela ordem do capital. O caráter classista, racista, excludente e seletivo mostra-se enraizado no sistema penal juvenil, deixando explícita a tentativa de manutenção da lógica da marginalização, da criminalização da pobreza e descarada naturalização da questão social.

Esse cenário traz como pano de fundo a perversidade da violação dos direitos de adolescentes e jovens, produzida e reproduzida em um modelo de sociedade que se sustenta pela órbita do capitalismo vigente, tal fato, nos provoca questionamentos - será que houve em algum momento da trajetória de vida desse grupo direitos que de fato foram assegurados?

Além disso, cabe considerar que a violação de direitos destes sujeitos representa um retrocesso das conquistas dos movimentos sociais e demais militantes, referente ao paradigma de proteção integral e da ampliação dos preceitos estabelecidos no ECA, o que traz à tona a urgente e necessária luta em defesa da garantia desses direitos, bem como a resistência frente às medidas de cunho repressivo/coercitivo, que mascaram a necessidade de manutenção da ordem socialmente estabelecida pelo capital em detrimento da ampliação de políticas públicas realmente capazes de sustentar um modelo de proteção social integral.

\section{Referências}

ADORNO, S. Justiça penal é mais severa com os criminosos negros. [Entrevista cedida a] Alexandre Zarias. ComCiência, Campinas, n. 49, nov. 2003. Disponível em: http://www.comciencia.br/dossies-1-72/entrevistas/negros/adorno.htm. Acesso em: 23 jan. 2019.

ARENDT, H. Sobre a violência. Rio de Janeiro: Civilização Brasileira, 2009.

BRASIL. Lei $n^{\circ} 8.069$ de 13 de julho de 1990. Dispõe sobre o Estatuto da Criança e do Adolescente e dá outras providências. Brasília, DF: Presidência da República, [2019]. Disponível em: http://www.planalto.gov.br/ccivil_03/LEIS/L8069.htm. Acesso em: 23 jan. 2019. BRASIL. Lei $n^{\circ} 12.852$, de 5 de agosto de 2013. Institui o Estatuto da Juventude e dispõe sobre os direitos dos jovens, os princípios e diretrizes das políticas públicas de juventude e o Sistema Nacional de Juventude - SINAJUVE. Brasília, DF: Presidência da República, [2018]. Disponível em: http:/www.planalto.gov.br/ccivil_03/_Ato2011-2014/2013/Lei/L12852.htm. Acesso em: 16 mar. 2018. BRASIL. Ministério dos Direitos Humanos. Levantamento anual SINASE 2015. Brasília: Ministério dos Direitos Humanos, 2018. BRASIL. Presidência da República. Secretaria de Governo. Índice de vulnerabilidade juvenil à violência 2017: desigualdade racial, municípios com mais de 100 mil. São Paulo: Fórum Brasileiro de Segurança Pública, 2017. 
BRASIL. Presidência da República. Secretaria Geral. Mapa do encarceramento: os jovens do Brasil. Brasília, DF: Presidência da República, 2015. (Série Juventude Viva).

CASTRO, A. Outrofobia: textos militantes. São Paulo: Publisher Brasil, 2016.

CERQUEIRA, D. et al. (coord.). Atlas da violência 2017. Rio de Janeiro: IPEA: FBSP, jun. 2017. Disponível em: http://www.ipea.gov.br/ atlasviolencia/download/2/2017. Acesso em: 5 abr. 2018.

FALEIROS, V. de P. Infância e processo político no Brasil. In: RIZZINI, I.; PILOTTI, F. (org.). A arte de governar crianças: a história das políticas sociais, da legislação e da assistência à infância no Brasil. 3. ed. São Paulo: Cortez, 2011. p. 33-96.

FAUSTINO, D. M. O encarceramento em massa e os aspectos raciais da exploração de classe no Brasil. PUCviva, São Paulo, n. 39, p. 14-27, set./dez. 2010

IAMAMOTO, M. V. Serviço social em tempo de capital fetiche: capital financeiro, trabalho e questão social. São Paulo: Cortez, 2011.

MARX, K. O capital: crítica da economia política: Livro 1: o processo de produção do capital. Rio de Janeiro: Bertrand Brasil, 1988. v. 1.

MENDEZ, E. G. Adolescentes e responsabilidade penal: um debate latino americano. Buenos Aires, fev. 2000. Disponível em: http:// justica21.web1119.kinghost.net/arquivos/bib_206.pdf. Acesso em: 12 mar. 2018.

MÉSZÁROS, I. Para além do capital. São Paulo: Boitempo, 2002.

PAULO NETTO, J. Cinco notas a propósito da "questão social". Temporalis, Brasília, ano 2, n. 3, p. 41-49, jan./jun. 2001. Disponível em: http://www.abepss.org.br/arquivos/anexos/temporalis_n_3_questao_social-201804131245276705850.pdf. Acesso em: 5 abr. 2018. PAULO NETTO, J. Desigualdade, pobreza e Serviço Social. Em Pauta, Rio de Janeiro, n. 19, p. 134-170, 2007.

RIZZINI, I. Crianças e menores do pátrio poder ao pátrio dever: um histórico da legislação para a infância no Brasil. In: RIZZINI, I.; PILOTTI, F. (org.). A arte de governar crianças: a história das politicas sociais, da legislação e da assistência à infância no Brasil. 3. ed. São Paulo: Cortez, 2011a. p. 97-149.

RIZZINI, I. Meninos desvalidos e menores transviados: a trajetória da assistência pública até a Era Vargas. In: RIZZINI, I.; PILOTTI, F. (org.). A arte de governar crianças: a história das políticas sociais, da legislação e da assistência à infância no Brasil. 3. ed. São Paulo: Cortez, 2011 b. p. 225-286.

RIZZINI, I. O século perdido: raízes históricas das políticas públicas para a infância no Brasil. 3. ed. São Paulo: Cortez, 2004.

SILVA, M. L. de O. Entre proteção e punição: o controle sociopenal dos adolescentes. São Paulo: Editora UNIFESP, 2011.

SIQUEIRA, L. Pobreza e Serviço Social: diferentes concepções e compromissos políticos. São Paulo: Cortez, 2013.

TAVARES, M. A. Acumulação, trabalho e desigualdades sociais. In: CONSELHO FEDERAL DE SERVIÇO SOCIAL; ASSOCIAÇÃO BRASILEIRA DE ENSINO E PESQUISA EM SERVIÇO SOCIAL (org.). Serviço Social: direitos sociais e competências profissionais. Brasília, DF: CFESS: ABEPSS, 2009. p. 239-254.

WACQUANT, L. As duas faces do gueto. São Paulo: Boitempo, 2008.

WACQUANT, L. As prisões da miséria. Rio de Janeiro: Jorge Zahar, 2001.

WAISELFISZ, J. J. Mapa da violência 2015: mortes matadas por arma de fogo. Brasília, DF: Secretaria-Geral da Presidência da República, 2015. (Série Juventude Viva).

\section{Bruna Carolina Bonalume}

bruna.bonalume@hotmail.com

Mestrado em Saúde Coletiva pela Universidade Estadual Paulista "Júlio Mesquita Filho" (Unesp)

Assistente Social do Tribunal de Justiça do Estado de São Paulo (TJSP)

\section{TJSP}

Comarca de São Manuel

Rua Ettore Targa , s/n - Centro

São Manuel - São Paulo - Brasil

CEP: $18.650-100$

\section{Adriana Giaqueto Jacinto}

drigiaqueto@gmail.com

Doutorado em Serviço Social pela Faculdade de Ciências Humanas e Sociais da Universidade Estadual Paulista "Júlio de Mesquita Filho" (Unesp)

Docente da Graduação e Pós-Graduação em Serviço Social na Faculdade de Ciências Humanas e Sociais da Universidade Estadual Paulista "Júlio de Mesquita Filho" (Unesp) 


\section{Unesp}

Rua Eufrásia Monteiro Petráglia, 900 - Jd. Dr. Antonio Petráglia

Franca - São Paulo - Brasil

CEP: $14.409-160$

\section{Agência financiadora \\ Não se aplica.}

\section{Contribuições das autoras}

Ambas as autoras contribuíram com a organização e elaboração do artigo. O mesmo é fruto das orientações realizadas durante o desenvolvimento do doutorado de Bruna Carolina Bonalume, tendo como orientadora a professora Adriana Giaqueto Jacinto.
Aprovação por Comitê de Ética e consentimento para participação

Não se aplica.

\section{Consentimento para publicação}

Não se aplica.

Conflito de interesses

Não há conflito de interesses. 